\title{
A MULTIPLE CRITERIA DECISION MAKING METHOD BASED ON RELATIVE VALUE DISTANCES
}

\author{
Huan-jyh SHYUR ${ }^{1}$, Liang YIN ${ }^{2}$, Hsu-shih SHIH ${ }^{3}$, Chi-bin CHENG ${ }^{4}$
}

\begin{abstract}
This paper proposes a new multiple criteria decision-making method called ERVD (election based on relative value distances). The s-shape value function is adopted to replace the expected utility function to describe the risk-averse and risk-seeking behavior of decision makers. Comparisons and experiments contrasting with the TOPSIS (Technique for Order Preference by Similarity to the Ideal Solution) method are carried out to verify the feasibility of using the proposed method to represent the decision makers' preference in the decision making process. Our experimental results show that the proposed approach is an appropriate and effective MCDM method.
\end{abstract}

Keywords: MCDM, prospect theory, value function, expected utility function, TOPSIS

${ }^{1}$ Department of Information Management, Tamkang University 151, Yingzhuan Rd., Tamsui Dist., New Taipei City 25137, Taiwan email: shyur@mail.im.tku.edu.tw

2 Department of Management Science, Tamkang University email: sherryyin@gmail.com

${ }^{3}$ Department of Management Science, Tamkang University email: hshih@mail.tku.edu.tw

${ }^{4}$ Department of Information Management, Tamkang University email: cbcheng@mail.tku.edu.tw 


\section{Introduction}

Multiple criteria decision making or multiple attributes decision making (MCDM/MADM) is an approach to dealing with structuring and solving decision and planning problems involving multiple criteria. A typical MCDM requires a comparison of the aggregated performance ratings. These comparison processes can be quite complex and produce results that may be unreliable. A lot of efforts have been devoted to developing methods for structuring and solving multiple criteria decision problems since the 1970s. When there is a non-dominate set of solutions to be compared and ranked, methods like TOPSIS (technique for order performance by similarity to ideal solution) [13], VIKOR [21], AHP (analytical hierarchical process) [23] or ELECTRE [2] are often used. All of these methods make use of preferences. However, the timing at which preference values are introduced varies across different methods.

The evaluations of the decision criteria of alternatives in the above methods are based on expected utility theory, with the assumption that the decision maker is rational, and may be risk averse. This implies that utility functions of the decision maker are concave and show diminishing marginal utility. Thus, practically, these methods start from the premise that the decision maker always looks for the solution corresponding to the maximum utility [9]. However, traditional utility theory cannot provide an adequate description of individual choice [15]. According to the principle of expected utility theory, the utility of a risky prospect is linear in outcome probability. From the point of view of cognitive psychology, Kahneman and Tversky [14] provided evidence that people have nonlinear preferences and tend to take risks to avoid losses. They proposed the prospect theory which uses the value function to describe and explain user behavior in the decision making process. They suggested that since individuals have different attitudes for dealing with risk based on their different reference points, and with an understanding of such risk-taking attitudes, human decision behavior can be better described.

The TOPSIS method was first introduced by Hwang and Yoon [13]. It is straightforward and easy to understand, and thus has become one of the most popular MCDM methods. It originates from the concept of a displaced ideal point from which the compromise solution has the shortest distance. The ranking of alternatives is based on the shortest distance from the positive ideal solution (PIS) and the farthest from the negative ideal solution (NIS). TOPSIS is a utility-based method that compares each alternative directly depending on the data in the evaluation matrices and weights [4]. The four advantages of TOPSIS has been described as [17,23]: (i) a sound logic that represents the rationale of human choice; (ii) a scalar value that accounts for both the best and worst alternatives simultaneously; (iii) a simple computation process that can be easily programmed into a spreadsheet; and (iv) the performance measures of all alternatives on attributes can be visualized on a polyhedron, at least for any two dimensions. Zanakis, Solomon, Wishart, and Dublish [31] made some comparisons with eight MCDM methods and found that TOPSIS has the fewest rank reversals. However, Wang and Luo [27] noted the problem of rank reversal in TOPSIS when the alternatives are close.

The present study revises TOPSIS and proposes a new MCDM method called ERVD (election based on relative value distances). It differs from TOPSIS in that the decision maker needs to identify reference points for each decision criterion in advanced. The value function determined by prospect theory is adopted to replace the utility function, to describe the risk-averse and risk-seeking behavior of decision makers, for the decision 
criteria, and as the basis for alternative ranking. Through the proposed technology, the relative value distances between the alternative and the positive ideal and negative ideal solution are measured to determine the ranking order of all the alternatives. The present study uses some numerical examples to compare the results of ERVD and TOPSIS. Our experiments show the ERVD has fewer ranking reversal problems than TOPSIS has. It appears to be more appropriate than other methods in dealing with decision makers' preference behavior.

This remainder of this paper is divided into five chapters. After a general introduction of TOPSIS and related works, ERVD is introduced. The method is demonstrated and verified in the model verification section. And then the conclusion and direction of future study are given in the final section.

\section{TOPSIS and Related works}

The Technique for Order of Preference by Similarity to Ideal Solution (TOPSIS) was firstly introduced by Hwang and Yoon [13], and further developed by Yoon [28], Chen and Hwang [3] and Lai, Liu, and Hwang [19]. Yue [30] established an extended TOPSIS model to deal with the problem that the attribute values are not precisely known but value ranges can be obtained. Baky and Abo-Sinna [1] proposed a fuzzy TOPSIS algorithm to solve bilevel multi-objective decision-making (BL-MODM) problems. The concept of TOPSIS is that the most preferred alternative should not only have the shortest distance from the positive ideal solution (PIS), but also have the longest distance from the negative ideal solution (NIS). Suppose there is an MCDM problem with $m$ alternatives, $A 1, \ldots, A m$, and $n$ decision criteria, $\mathrm{C} 1, \ldots, \mathrm{C} n$. The decision problem is expressed in the following matrix format:

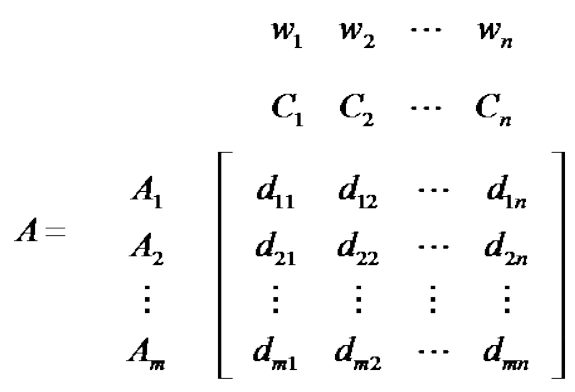

where $d_{i j}$ represents the rating of alternative $A_{i}$ under criterion $C_{j}$, and $w_{j}$ is the relative weight of criterion $C_{j}$. Then the following steps can be carried out in TOPSIS:

Step 1: Create the normalized decision matrix.

With this normalization each criterion has the same unit scale. Shih et al. [23] summarized different operating operations in the step corresponding to normalization. In traditional TOPSIS, the value $r_{i j}$ in the normalized decision matrix can be obtained by using the equation given below: 


$$
r_{\bar{y}}=\frac{d_{\bar{y}}}{\sqrt{\sum_{i=1}^{m} d_{\bar{y}}^{2}}}, i=1, \ldots, m ; j=1, \ldots, n .
$$

Step 2: Calculate the weighted normalized decision matrix The weighted normalized value $v_{i j}$ is calculated as follows:

$\boldsymbol{v}_{i j}=w_{j} \cdot r_{i j}, i=1, \ldots, m ; j=1, \ldots, n$;

where $\sum_{j=1}^{n} w_{j}=1$.

Step 3: Find the positive-ideal and negative-ideal solution The positive-ideal solution (PIS) $A^{+}$and negative-ideal solution (NIS) $A^{\square}$ are determined as follows:

$$
\begin{aligned}
& A^{+}=\left\{v_{1}^{+}, \cdots, v_{n}^{+}\right\}, \\
& A^{-}=\left\{v_{1}^{-}, \cdots, v_{n}^{-}\right\},
\end{aligned}
$$

where

$v_{j}^{+}=\left\{\left(\max _{\bar{i}} v_{\bar{y}} \mid j \in J\right)\left(\min _{\bar{i}} v_{\bar{y}} \mid j \in J^{\prime}\right)\right\}$ and

$v_{\bar{j}}^{-}=\left\{\left(\min _{\bar{i}} v_{\bar{y}} \mid j \in J\right)\left(\max _{\bar{i}} v_{\bar{y}} \mid j \in J^{\prime}\right)\right\} . J$ is associated with benefit criteria, and $J^{\prime}$ is associated with cost criteria.

Step 4: Calculate the separation measures

The individual separation measures of each alternative from the PIS and NIS are computed through Euclidean distance and calculated as:

$$
\begin{aligned}
& S_{i}^{+}=\sqrt{\sum_{j=1}^{n}\left(v_{j}^{+}-v_{i j}\right)^{2}}, i=1, \ldots, m \\
& S_{i}^{-}=\sqrt{\sum_{j=1}^{n}\left(v_{i j}-v_{j}^{-}\right)^{2}}, i=1, \ldots, m .
\end{aligned}
$$

Step 5: Calculate the relative closeness of each alternative to the ideal solution

The closeness coefficient $\phi_{i}$ to the ideal solution can be expressed as follows:

$$
\phi_{i}=\frac{S_{i}^{-}}{S_{i}^{+}+S_{i}^{-}}, i=1, \ldots, m
$$

where the value of $\phi_{i}$ lies between 0 and 1 .

Step 6: Rank the solutions according to the relative closeness to the ideal solution. 
A larger closeness coefficient value means that the solution is closer to the ideal solution for the alternatives.

Opricovic and Tzeng [22] argued that although TOPSIS is supposed to produce the best alternative, i.e., the shortest distance from the positive ideal solution and the longest distance from the negative ideal solution, it does not definitely so. Wang and Luo [27] note the problem of rank reversal in TOPSIS when the alternatives are close. Some studies have mentioned that this problem may occur because TOPSIS does not consider the relative importance of distances for each alternative from the ideal solution and from the negativeideal solution [22,29]. Deng, Yehm, and Willis [5] modified the TOPSIS method to solve this problem. Opricovic [21] proposed the VIKOR method to find the compromised alternative. This method makes use of the multi-criteria ranking index based on the particular measure of "closeness" to the "ideal" solution. Ju and Wang [14] extended the VIKOR method to solve multi-criteria group decision making problems in which both the criteria values and criteria weights take the form of linguistic information.

Kahneman and Trersky [15] discovered that human decision behavior is actually relative under uncertainty, meaning that some individuals are risk-seeking, and some practice risk-aversion. In most situations, risk is to be avoided. Prospect theory replaces the utility function and probability with the value function and weight function. By using the value function, the relative values of decision results are represented under different decision conditions (better or worse than the reference point). By definition, the curve of the value function goes through the reference point of the decision maker and is shaped like an S curved line as in the picture below; thus, it is also called the S-function (see figure 1). The gain (better than the reference point) shows as convex curve and the loss (worse than the reference point) a concave curve, and the decreasing concave slope is steeper than the increasing convex one.

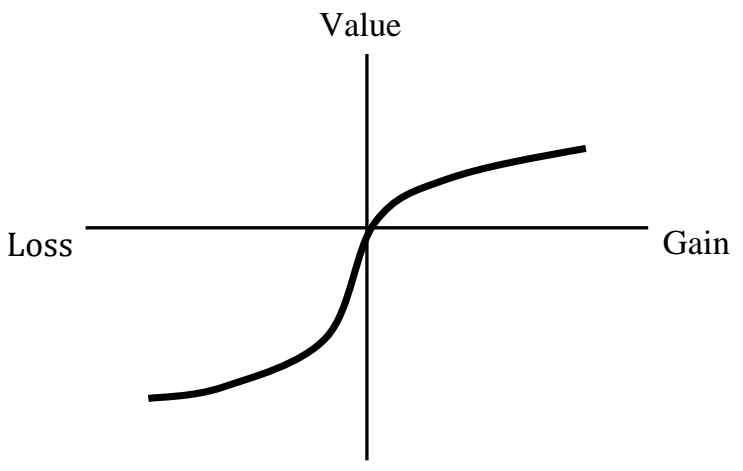

Figure 1. Value Function [14]

Trersky and Kahneman defined the three characteristics of the value function [25]: (1) reference dependence; (2) diminishing sensitivity; and (3) loss aversion. Reference dependence refers to the fact that human cognitive ability is based on relative value changes, which is also referred to as the endowment effect or status quo bias, and with the consideration for costs, current status tends to be kept unchanged. Diminishing sensitivity is defined by the decreasing utility as the gain increases. Finally, as for loss aversion, we feel more pain due to losses than happiness resulting from gains. Cumulative Prospect Theory is a further development of prospect theory [25]. In Cumulative Prospect Theory, 
the weighted cumulative probability is applied to replace the cumulative probability of outcome.

Prospect theory has been widely used as behavioral model of decision-making under risk, mainly in economics and finance [6,11,12]. In current MCDM studies, attitudes towards risk are seldom taken into consideration. One of the first MCDM methods related to prospect theory was TODIM (an acronym in Portuguese for iterative multi-criteria decision making) proposed by Gomes and Lima [7]. The method makes use of pair comparisons between the decision criteria, using technically simple resources to eliminate occasional inconsistencies arising from these comparisons [8]. According to prospect theory, decision makers decide which outcomes they consider equivalent set a reference point and then consider lesser outcomes as losses and greater ones as gains. TODIM, however, uses a different way, by using pair comparisons between decision criteria and the reference points are not determined initially. When comparing alternative $A_{i}$ with alternative $A_{j}$ under criterion $c$, a gain is assumed if the outcome of alternative $A_{i}$ is larger than alternative $A_{j}$, it is a gain; and if the outcome of alternative $A_{i}$ is smaller than alternative $A_{j}$, it is a loss. TODIM makes use of a Prospect Theory type of value function that is algebraically quite similar to Cumulative Prospect Theory's value function. The trade-off weighting factors of TODIM are interpreted as probabilities. Although TODIM does not deal with risk directly, it deals with the risk attitude of decision maker [10]. Wang et. al., [26] extend TOPSIS and TODIM method using hesitant fuzzy linguistic numbers to describe the preferences of decision makers. They find the TODIM method is more practical than the TOPSIS method when solving practical decision-making problems. Lourenzutti and Krohling [20] brought the Hellinger distance to the MCDM context to assist TOPSIS and TODIM to deal with the situation that the ratings of alternatives are not real numbers. Khamseh and Mahmoodi [16] use fuzzy TOPSIS to evaluate initial weight of each criterion, and then use TODIM to evaluate the final weight of each criterion against alternatives and the relationship between criteria.

\section{The ERVD Method}

In TOPSIS, if we consider the outcome of $A_{i}$ as a reference point, then the outcome of PIS can be considered as a gain and the outcome of NIS as a loss. The value function can be used to explore the relative importance of the distances for each alternative from the positive ideal solution and the negative ideal solution. ERVD is a discrete multi-criteria decision making method based on cumulated prospect theory [25]. It differs from TOPSIS in that the decision maker needs to identify reference points for each decision criterion in advanced. The use of ERVD replaces the traditional expected utility function for multicriteria with a global value function. The value function is created based on the gains/losses function of Cumulative Prospect Theory [25]. This function is built in parts, with the mathematical descriptions reproducing the gain/loss function of prospect theory. 
The proposed method can be summarized as follows:

Step 1. Define reference points $\mu_{j}, j=1, \ldots, n$, for each decision criterion:

According to prospect theory, the distance between the reference point and the outcome, not the outcome itself, is used to make the final decision. This means that value is defined in terms of gain and loss not the final outcome. The condition of our preference implies the existence of reference points for each of the decision criteria. Decision makers must decide which outcomes they consider equivalent for criterion $j$, set the reference point $\mu_{j}$ and then consider lesser outcomes as losses and greater ones as gains.

Step 2. Construct the normalized decision matrix $N$ :

To compare the alternatives for each criterion, a linear scale transformation is used to transform the various criteria scales into a comparable scale. The normalized value $r_{i j}$ of the decision matrix is calculated as

$r_{i j}=\frac{d_{i j}}{\sum_{i=1}^{m} d_{i j}}$

Then, we can obtain the normalized decision matrix $N=\left[r_{i j}\right]_{m \times n}$. Note that we assume that the available data is complete in the given decision matrix, including quantitative and qualitative information. The normalization of qualitative data or linguistic data can be first transformed to a linear scale, e.g., 1-10; in such cases, the above method is applicable.

Step 3. Transform the reference points into the normalized scale:

The reference point for each criterion is also transformed into the same scale by the following equations.

$\varphi_{j}=\frac{\mu_{j}}{\sum_{i=1}^{m} d_{i j}}$

Step 4. Calculate the value of alternative $A_{i}$ according to criterion $C_{j}$ :

By modifying the Tversky and Kahneman's function [25], this study employs two types of value functions, increasing value function and decreasing value function, which possess a two-part power form.

Increasing value function:

$v_{i j}=\left\{\begin{array}{l}\left(r_{i j}-\varphi_{j}\right)^{\alpha} \quad \text { if } r_{i j}>\varphi_{j} \\ -\lambda\left(\varphi_{j}-r_{i j}\right)^{\alpha} \text { otherwise }\end{array}\right.$

Decreasing value function:

$v_{i j}=\left\{\begin{array}{l}\left(\varphi_{j}-r_{i j}\right)^{\alpha} \quad \text { if } r_{i j}<\varphi_{j} \\ -\lambda\left(r_{i j}-\varphi_{j}\right)^{\alpha} \text { otherwise }\end{array}\right.$ 
The parameter $\lambda$ represents the attenuation factor of the losses, which can be tuned according to the problem at hand. $\alpha$ is the diminishing sensitivity parameters. The diminishing sensitivity parameter $\alpha<1$ yields an S-shape value function; $\alpha>1$ produces an inverse S-shape value function. The increasing value function will be assigned to represent the preference of benefit criteria. For benefit criteria, the rating that is larger than the reference point is viewed as a gain. Oppositely, if the rating that is larger than the reference point is viewed as a loss, then a decreasing form of value function will be assigned. As a consequence, a value based decision matrix representing the relative performance of the alternatives is obtained as

$$
V=\left[\begin{array}{cccc}
v_{11} & v_{12} & \cdots & v_{1 n} \\
v_{21} & v_{22} & \cdots & v_{2 n} \\
\cdots & \cdots & \cdots & \cdots \\
v_{m 1} & v_{m 2} & \cdots & v_{m n}
\end{array}\right]
$$

Step 5. Determine the ideal and negative ideal solutions $A^{+}$(PIS) and $A^{-}$(NIS), respectively:

According to the normalized value based decision matrix, we can determine the positive ideal solution $A^{+}$and negative ideal solution $A^{-}$in order to analyze the psychological value distance between the ideal and negative-ideal solutions for each alternative, as follows:

$$
A^{+}=\left\{v_{1}^{+}, \cdots v_{n}^{+}\right\}, A^{-}=\left\{v_{1}^{-}, \cdots v_{n}^{-}\right\},
$$

where $v_{j}^{+}=\max _{i} v_{i j}$ and $v_{j}^{-}=\min _{i} v_{\ddot{y}}$.

PIS and NIS can be interpreted as "imaginary outcomes" representing the best possible and worst possible values of criteria in current decision problem.

Step 6. Calculate the separation measures from PIS and NIS individually:

The individual separation measures of each alternative from the PIS and NIS are

$S_{i}^{+}=\sum_{j=1}^{n} w_{j} \cdot\left|v_{i j}-v_{j}^{+}\right|$, for alternative $i, i=1 \ldots m$,

$S_{i}^{-}=\sum_{j=1}^{n} \boldsymbol{w}_{j} \cdot\left|\boldsymbol{v}_{i j}-\boldsymbol{v}_{j}^{-}\right|$, for alternative $i, i=1 \ldots m$,

where $\|$ is a Minkowski's $L_{p}$ metric [18]. The Minkowski distance of order $p$ between two points $x, y \in R^{n}$ is defined as $L_{p}(x, y)=\left(\sum_{i=1}^{n}\left|x_{i}-y_{i}\right|^{p}\right)^{1 / p}$. The two measures in equation (10) represent the weighted value distances of alternative $i$ to the PIS and NIS.

Step 7. Calculate the relative closeness of each alternative to the ideal solution: $\phi_{i}=\frac{S_{i}^{-}}{S_{i}^{+}+S_{i}^{5}}, i=1, \ldots, m$.

$\phi_{i}$ is a number between 0 and 1 ; the bigger this values is, the closer this alternative is to the 
positive ideal solution, and the further it is to the negative ideal solution. Thus, the alternative should be ranked higher.

Like TOPSIS, if the separation measures from PIS and NIS are considered to compute through weighted absolute distance. Step 5 and 6 can be further replaced by simple weighted sum model. The importance of alternative $i$ is defined as

$\theta_{i}=\sum_{j=1}^{n} w_{j} \cdot v_{i j}$

The best alternative is the one that yields the maximum total performance value.

Next we illustrate the process of the proposed model through an example provided by Shih et al. [24]. A chemical company must choose an on-line manager from 17 qualified candidates. The alternatives are evaluated as presented in Table 1. All 7 criteria are benefit criteria and their weights are shown in Table 2.

Table 1. Decision matrix of human resource selection [21]

\begin{tabular}{|c|c|c|c|c|c|c|c|}
\hline Alt. & \multicolumn{7}{|c|}{ Criteria } \\
\cline { 2 - 8 } & $\begin{array}{c}\text { Language } \\
\text { Test } \\
\left(\mathrm{C}_{1}\right)\end{array}$ & $\begin{array}{c}\text { Professional } \\
\text { Test } \\
\left(\mathrm{C}_{2}\right)\end{array}$ & $\begin{array}{c}\text { Safety Rule } \\
\text { Test } \\
\left(\mathrm{C}_{3}\right)\end{array}$ & $\begin{array}{c}\text { Professional } \\
\text { Skills } \\
\left(\mathrm{C}_{4}\right)\end{array}$ & $\begin{array}{c}\text { Computer } \\
\text { Skills }\left(\mathrm{C}_{5}\right)\end{array}$ & $\begin{array}{c}\text { Panel } \\
\text { Interview } \\
\left(\mathrm{C}_{6}\right)\end{array}$ & $\begin{array}{c}\text { 1-on-1 } \\
\text { Interviews } \\
\left(\mathrm{C}_{7}\right)\end{array}$ \\
\hline $\mathrm{A}_{1}$ & 80 & 70 & 87 & 77 & 76 & 80 & 75 \\
\hline $\mathrm{A}_{2}$ & 85 & 65 & 76 & 80 & 75 & 65 & 75 \\
\hline $\mathrm{A}_{3}$ & 78 & 90 & 72 & 80 & 85 & 90 & 85 \\
\hline $\mathrm{A}_{4}$ & 75 & 84 & 69 & 85 & 65 & 65 & 70 \\
\hline $\mathrm{A}_{5}$ & 84 & 67 & 60 & 75 & 85 & 75 & 80 \\
\hline $\mathrm{A}_{6}$ & 85 & 78 & 82 & 81 & 79 & 80 & 80 \\
\hline $\mathrm{A}_{7}$ & 77 & 83 & 74 & 70 & 71 & 65 & 70 \\
\hline $\mathrm{A}_{8}$ & 78 & 82 & 72 & 80 & 78 & 70 & 60 \\
\hline $\mathrm{A}_{9}$ & 85 & 90 & 80 & 88 & 90 & 80 & 85 \\
\hline $\mathrm{A}_{10}$ & 89 & 75 & 79 & 67 & 77 & 70 & 75 \\
\hline $\mathrm{A}_{11}$ & 65 & 55 & 68 & 62 & 70 & 50 & 60 \\
\hline $\mathrm{A}_{12}$ & 70 & 64 & 65 & 65 & 60 & 60 & 65 \\
\hline $\mathrm{A}_{13}$ & 95 & 80 & 70 & 75 & 70 & 75 & 75 \\
\hline $\mathrm{A}_{14}$ & 70 & 80 & 79 & 80 & 85 & 80 & 70 \\
\hline $\mathrm{A}_{15}$ & 60 & 78 & 87 & 70 & 66 & 70 & 65 \\
\hline $\mathrm{A}_{16}$ & 92 & 85 & 88 & 90 & 85 & 90 & 95 \\
\hline $\mathrm{A}_{17}$ & 86 & 87 & 80 & 70 & 72 & 80 & 85 \\
\hline
\end{tabular}

Table 2. Weights on criteria [21]

\begin{tabular}{|l|l|c|}
\hline & \multicolumn{1}{|c|}{ Criteria } & The Weights \\
\hline $\mathrm{C}_{1}$ & Language Test & 0.066 \\
\hline $\mathrm{C}_{2}$ & Professional Test & 0.196 \\
\hline $\mathrm{C}_{3}$ & Safety Rule Test & 0.066 \\
\hline $\mathrm{C}_{4}$ & Professional Skills & 0.130 \\
\hline $\mathrm{C}_{5}$ & Computer Skills & 0.130 \\
\hline $\mathrm{C}_{6}$ & Panel Interview & 0.216 \\
\hline $\mathrm{C}_{7}$ & 1-on-1 Interviews & 0.196 \\
\hline & Sum & 1 \\
\hline
\end{tabular}

In addition, we assume the baseline score or reference point to be 80 for each criterion. The normalized decision matrix $N$ and reference points can be create by equation (6) and (7), respectively. Table 3 illustrates the results. 
Table 3. Normalized decision matrix

\begin{tabular}{|l|c|c|c|c|c|c|c|}
\hline \multirow{2}{*}{ Alternatives } & \multicolumn{7}{|c|}{ Criteria } \\
\cline { 2 - 8 } & $\mathrm{C}_{1}$ & $\mathrm{C}_{2}$ & $\mathrm{C}_{3}$ & $\mathrm{C}_{4}$ & $\mathrm{C}_{5}$ & $\mathrm{C}_{6}$ & $\mathrm{C}_{7}$ \\
\hline $\mathrm{A}_{1}$ & 0.059 & 0.053 & 0.068 & 0.059 & 0.059 & 0.064 & 0.059 \\
\hline $\mathrm{A}_{2}$ & 0.063 & 0.050 & 0.059 & 0.062 & 0.058 & 0.052 & 0.059 \\
\hline $\mathrm{A}_{3}$ & 0.058 & 0.069 & 0.056 & 0.062 & 0.066 & 0.072 & 0.067 \\
\hline $\mathrm{A}_{4}$ & 0.055 & 0.064 & 0.054 & 0.066 & 0.050 & 0.052 & 0.055 \\
\hline $\mathrm{A}_{5}$ & 0.062 & 0.051 & 0.047 & 0.058 & 0.066 & 0.060 & 0.063 \\
\hline $\mathrm{A}_{6}$ & 0.063 & 0.059 & 0.064 & 0.063 & 0.061 & 0.064 & 0.063 \\
\hline $\mathrm{A}_{7}$ & 0.057 & 0.063 & 0.057 & 0.054 & 0.055 & 0.052 & 0.055 \\
\hline $\mathrm{A}_{8}$ & 0.058 & 0.062 & 0.056 & 0.062 & 0.061 & 0.056 & 0.047 \\
\hline $\mathrm{A}_{9}$ & 0.063 & 0.069 & 0.062 & 0.068 & 0.070 & 0.064 & 0.067 \\
\hline $\mathrm{A}_{10}$ & 0.066 & 0.057 & 0.061 & 0.052 & 0.060 & 0.056 & 0.059 \\
\hline $\mathrm{A}_{11}$ & 0.048 & 0.042 & 0.053 & 0.048 & 0.054 & 0.040 & 0.047 \\
\hline $\mathrm{A}_{12}$ & 0.052 & 0.049 & 0.050 & 0.050 & 0.047 & 0.048 & 0.051 \\
\hline $\mathrm{A}_{13}$ & 0.070 & 0.061 & 0.054 & 0.058 & 0.054 & 0.060 & 0.059 \\
\hline $\mathrm{A}_{14}$ & 0.052 & 0.061 & 0.061 & 0.062 & 0.066 & 0.064 & 0.055 \\
\hline $\mathrm{A}_{15}$ & 0.044 & 0.059 & 0.068 & 0.054 & 0.051 & 0.056 & 0.051 \\
\hline $\mathrm{A}_{16}$ & 0.068 & 0.065 & 0.068 & 0.069 & 0.066 & 0.072 & 0.075 \\
\hline $\mathrm{A}_{17}$ & 0.064 & 0.066 & 0.062 & 0.054 & 0.056 & 0.064 & 0.067 \\
\hline Reference Points & 0.059 & 0.061 & 0.062 & 0.062 & 0.062 & 0.064 & 0.063 \\
\hline
\end{tabular}

The next step is going to calculate the value of each alternative with respect to each criterion using equation (8) and (9). Kahneman and Tversky [15] experimentally determined the values of $\lambda=2.25$ and $\alpha=0.88$ which are consistent with empirical data. Furthermore, they suggest that the value of $\lambda$ can be between 2.0 and 2.5. In tis experiment, we assume $\lambda=2.25$ and $\alpha=0.88$. Using these parameters, the normalized value based decision matrix is created as shown in Table 4. On the basis of the prospect theory value function, the negative values represent the losses and positive values represent gains. Then, we can determine the ideal and negative ideal solutions $\mathrm{A}^{+}$(PIS) and $\mathrm{A}^{-}$(NIS). $\mathrm{A}^{+}$is $\{0.019,0.014,0.011,0.014,0.014,0.014,0.02\}$ and $A^{-}$is $\{-0.055,-0.069,-0.058,-0.052,-$ $0.058,-0.085,-0.058\}$.

Table 4. Normalized value based decision matrix

\begin{tabular}{|l|l|l|l|l|l|l|l|}
\hline \multirow{2}{*}{ Alternatives } & \multicolumn{7}{|c|}{ Criteria } \\
\cline { 2 - 8 } & $\mathrm{C}_{1}$ & $\mathrm{C}_{2}$ & $\mathrm{C}_{3}$ & $\mathrm{C}_{4}$ & $\mathrm{C}_{5}$ & $\mathrm{C}_{6}$ & $\mathrm{C}_{7}$ \\
\hline $\mathrm{A}_{1}$ & 0.000 & -0.031 & 0.010 & -0.011 & -0.014 & 0.000 & -0.017 \\
\hline $\mathrm{A}_{2}$ & 0.007 & -0.044 & -0.014 & 0.000 & -0.017 & -0.046 & -0.017 \\
\hline $\mathrm{A}_{3}$ & -0.007 & 0.014 & -0.026 & 0.000 & 0.008 & 0.014 & 0.008 \\
\hline $\mathrm{A}_{4}$ & -0.016 & 0.006 & -0.034 & 0.008 & -0.045 & -0.046 & -0.032 \\
\hline $\mathrm{A}_{5}$ & 0.006 & -0.039 & -0.058 & -0.017 & 0.008 & -0.018 & 0.000 \\
\hline $\mathrm{A}_{6}$ & 0.007 & -0.007 & 0.003 & 0.002 & -0.004 & 0.000 & 0.000 \\
\hline $\mathrm{A}_{7}$ & -0.010 & 0.005 & -0.020 & -0.031 & -0.029 & -0.046 & -0.032 \\
\hline $\mathrm{A}_{8}$ & -0.007 & 0.003 & -0.026 & 0.000 & -0.008 & -0.032 & -0.058 \\
\hline $\mathrm{A}_{9}$ & 0.007 & 0.014 & 0.000 & 0.011 & 0.014 & 0.000 & 0.008 \\
\hline $\mathrm{A}_{10}$ & 0.012 & -0.017 & -0.004 & -0.039 & -0.011 & -0.032 & -0.017 \\
\hline $\mathrm{A}_{11}$ & -0.043 & -0.069 & -0.037 & -0.052 & -0.031 & -0.085 & -0.058 \\
\hline $\mathrm{A}_{12}$ & -0.030 & -0.047 & -0.045 & -0.044 & -0.058 & -0.059 & -0.045 \\
\hline $\mathrm{A}_{13}$ & 0.019 & 0.000 & -0.031 & -0.017 & -0.031 & -0.018 & -0.017 \\
\hline $\mathrm{A}_{14}$ & -0.030 & 0.000 & -0.004 & 0.000 & 0.008 & 0.000 & -0.032 \\
\hline
\end{tabular}




\begin{tabular}{|l|l|l|l|l|l|l|l|}
\hline $\mathrm{A}_{15}$ & -0.055 & -0.007 & 0.010 & -0.031 & -0.042 & -0.032 & -0.045 \\
\hline $\mathrm{A}_{16}$ & 0.016 & 0.007 & 0.011 & 0.014 & 0.008 & 0.014 & 0.020 \\
\hline $\mathrm{A}_{17}$ & 0.008 & 0.010 & 0.000 & -0.031 & -0.026 & 0.000 & 0.008 \\
\hline
\end{tabular}

Finally we can calculate the separation measures and the relative closeness for each alternative as illustrated in Table 5. The separation measures from PIS and NIS are computed through weighted absolute distance. The results show that candidate $A_{16}$ is ranked first, and Candidate $A_{11}$ is ranked last. These findings correspond with those of previous studies.

Table 5. The relative closeness and rank by ERVD

\begin{tabular}{|c|c|c|c|c|}
\hline \multirow[b]{2}{*}{ Alternatives } & \multicolumn{2}{|c|}{ Separation Measures } & \multirow{2}{*}{$\begin{array}{c}\text { Relative Closeness } \\
\boldsymbol{\phi}_{\boldsymbol{i}}\end{array}$} & \multirow[b]{2}{*}{ Rank } \\
\hline & $S_{\bar{i}}^{+}$ & $S_{\bar{i}}^{-}$ & & \\
\hline$A_{1}$ & 0.027 & 0.053 & 0.660 & 7 \\
\hline $\mathrm{A}_{2}$ & 0.040 & 0.040 & 0.503 & 13 \\
\hline $\mathrm{A}_{3}$ & 0.009 & 0.071 & 0.885 & 3 \\
\hline $\mathrm{A}_{4}$ & 0.038 & 0.042 & 0.521 & 12 \\
\hline$A_{5}$ & 0.031 & 0.049 & 0.610 & 9 \\
\hline $\mathrm{A}_{6}$ & 0.016 & 0.064 & 0.796 & 4 \\
\hline $\mathrm{A}_{7}$ & 0.040 & 0.040 & 0.498 & 14 \\
\hline $\mathrm{A}_{8}$ & 0.036 & 0.044 & 0.549 & 11 \\
\hline$A_{9}$ & 0.007 & 0.073 & 0.908 & 2 \\
\hline$A_{10}$ & 0.035 & 0.045 & 0.565 & 10 \\
\hline$A_{11}$ & 0.075 & 0.006 & 0.070 & 17 \\
\hline$A_{12}$ & 0.064 & 0.016 & 0.199 & 16 \\
\hline$A_{13}$ & 0.030 & 0.051 & 0.632 & 8 \\
\hline$A_{14}$ & 0.023 & 0.057 & 0.716 & 6 \\
\hline$A_{15}$ & 0.045 & 0.035 & 0.438 & 15 \\
\hline $\mathrm{A}_{16}$ & 0.002 & 0.078 & 0.972 & 1 \\
\hline$A_{17}$ & 0.019 & 0.062 & 0.767 & 5 \\
\hline
\end{tabular}

\section{Experimental Results}

To evaluate the proposed method, four experiments are conducted to demonstrate the performance of ERVD and uncover the irrational results of TOPSIS.

Experiment 1:

A problem of TOPSIS is that it may derive a false preference ranking when two alternatives are very close. In this experiment, a decision maker must choose an alternative from a set of 5 alternatives, i.e. $\left\{A_{1}, A_{2}, A_{3}, A_{4}, A_{5}\right\}$. Two benefit criteria with equal weights are used to evaluate the 5 alternatives. The evaluation results are presented in Table 6. Both of the methodologies use the same linear normalization method to obtain the normalized decision matrix.

TOPSIS and ERVD provide different ranking results. Using the TOPSIS method, $\mathrm{A}_{4}$ should be the best alternative since it has the highest closeness coefficient value $\boldsymbol{\phi}_{\boldsymbol{i}}$ with respect to the other alternatives. However, it seems the total utility level of $\mathrm{A}_{5}$ $(75 * 0.5+76 * 0.5=75.5)$ is higher than $\mathrm{A}_{4}(80 * 0.5+70 * 0.5=75)$, while the two criteria have the same weight. If we only consider $\mathrm{A}_{4}$ and $\mathrm{A}_{5}$ as the alternatives and use the TOPSIS 
method to evaluate $A_{4}$ and $A_{5}$, then the ranking order of the two alternatives will be different. The closeness coefficient values of $A_{4}$ and $A_{5}$ are 0.44 and 0.56 , respectively. Oppositely, the evaluation results are more robust when we apply ERVD in this experiment. If only $A_{4}$ and $A_{5}$ are considered in the choice set, $A_{5}$ still has higher closeness coefficient value than $\mathrm{A}_{4}\left(\mathrm{~A}_{4}: 0.433\right.$ and $\left.\mathrm{A}_{5}: 0.567\right)$. Why TOPSIS provides different ranking results in this case? The problem may be caused by the general definition of what TOPSIS really does. According to TOPSIS, the decision maker's preferences are defined as criteria weights only, and the ranking of alternatives are based on the weighted distances between its outcome and both the PIS and the NIS. It makes the ranking of each alternative is more dependent on the outcomes of other alternatives (especially dependent on the alternatives whose outcomes influence PIS and/or NIS). In ERVD the decision maker's preferences are defined as criteria weights and reference points. The original decision matrix will be transferred to the value based decision matrix. Not only the performances of other alternatives but also the reference points will influence the final ranking results. It makes the ERVD method more robust.

Table 6. The decision matrix and results obtained by TOPSIS and ERVD of experiment 1

\begin{tabular}{|c|c|c|c|c|c|c|c|c|c|c|}
\hline \multirow{2}{*}{ Alternatives } & \multicolumn{2}{|c|}{ Criteria } & \multicolumn{4}{|c|}{ TOPSIS } & \multicolumn{4}{|c|}{ ERVD } \\
\hline & $\mathrm{C}_{1}$ & $\mathrm{C}_{2}$ & $S_{i}^{+}$ & $S_{i}^{-}$ & $\phi_{i}$ & Rank & $S_{i}^{+}$ & $S_{i}^{-}$ & $\phi_{\bar{i}}$ & Rank \\
\hline $\mathrm{A}_{1}$ & 85 & 50 & 0.039 & 0.068 & 0.634 & 3 & 0.087 & 0.147 & 0.629 & 3 \\
\hline $\mathrm{A}_{2}$ & 40 & 64 & 0.071 & 0.021 & 0.231 & 5 & 0.172 & 0.062 & 0.266 & 5 \\
\hline $\mathrm{A}_{3}$ & 50 & 70 & 0.054 & 0.034 & 0.386 & 4 & 0.115 & 0.118 & 0.507 & 4 \\
\hline $\mathrm{A}_{4}$ & 80 & 70 & 0.012 & 0.068 & 0.851 & 1 & 0.021 & 0.213 & 0.910 & 2 \\
\hline $\mathrm{A}_{5}$ & 75 & 76 & 0.015 & 0.066 & 0.813 & 2 & 0.019 & 0.215 & 0.920 & 1 \\
\hline $\begin{array}{l}\text { Reference } \\
\text { Points }\end{array}$ & 60 & 60 & & & & & & & & \\
\hline Weights & 0.5 & 0.5 & & & & & & & & \\
\hline
\end{tabular}

Experiment 2:

In this experiment, we present situations in which all alternatives have the same total utility. Suppose the decision problem has 5 alternatives in the choice set and 2 benefit criteria with the same weights to be evaluated. Table 7 presents the basic data and evaluation results.

Using TOPSIS, the relative coefficients of alternatives $A_{1}, A_{2}, A_{3}, A_{4}$, and $A_{5}$ have the same value. In this situation, we cannot distinguish the preference of the choice set. TOPSIS does not seem to be an effective method to deal with a situation where alternatives have the same total utility. It is remarkable that ERVD has no problem evaluating the performance of all the alternatives. This is because the relative coefficients are calculated based on psychological distance. The value of each alternative with respect to each criterion is expressed by means of gains and losses from a reference point. The reference points and value function, which capture psychological aspects of decision making under risk, help to measure the value of the assigned rating of each alternative. We decide the reference points $\mu_{1}=60$ and $\mu_{2}=70$ in this case. This infers that we have a higher 
expectation for $C_{2}$. For example, alternatives $A_{1}$ and $A_{5}$ have the assigned ratings of $(0,100)$ and $(100,0)$, respectively. The rating for $A_{5}$ with respect to $C_{2}$ is 0 , which shows that our loss is 70 . The rating for $A_{1}$ with respect to $C_{1}$ is 0 , which shows that our loss is 60 . Thus, $A_{1}$ has a higher ranking order than does $A_{5}$.

Table 7. The decision matrix and results obtained by TOPSIS and ERVD of experiment 2

\begin{tabular}{|l|c|c|c|c|c|c|c|c|c|c|}
\hline \multirow{2}{*}{ Alt. } & \multicolumn{2}{|c|}{ Criteria } & \multicolumn{4}{|c|}{ TOPSIS } & \multicolumn{4}{|c|}{ ERVD } \\
\cline { 2 - 12 } & $\mathrm{C}_{1}$ & $\mathrm{C}_{2}$ & $\boldsymbol{S}_{\boldsymbol{i}}^{+}$ & $\boldsymbol{S}_{\boldsymbol{i}}$ & $\boldsymbol{\phi}_{\boldsymbol{i}}$ & Rank & $\boldsymbol{S}_{\boldsymbol{i}}^{+}$ & $\boldsymbol{S}_{\boldsymbol{i}}^{-}$ & $\boldsymbol{\phi}_{\boldsymbol{i}}$ & Rank \\
\hline $\mathrm{A}_{1}$ & 0 & 100 & 0.200 & 0.200 & 0.500 & 1 & 0.420 & 0.444 & 0.514 & 4 \\
\hline $\mathrm{A}_{2}$ & 30 & 70 & 0.152 & 0.152 & 0.500 & 1 & 0.351 & 0.513 & 0.594 & 1 \\
\hline $\mathrm{A}_{3}$ & 50 & 50 & 0.141 & 0.141 & 0.500 & 1 & 0.365 & 0.499 & 0.578 & 2 \\
\hline $\mathrm{A}_{4}$ & 70 & 30 & 0.152 & 0.152 & 0.500 & 1 & 0.372 & 0.493 & 0.570 & 3 \\
\hline $\mathrm{A}_{5}$ & 100 & 0 & 0.200 & 0.200 & 0.500 & 1 & 0.444 & 0.420 & 0.486 & 5 \\
\hline $\begin{array}{l}\text { Reference } \\
\text { Points }\end{array}$ & 60 & 70 & & & & & & & & \\
\hline Weights & 0.5 & 0.5 & & & & & & & & \\
\hline
\end{tabular}

Experiment 3:

This experiment tests the effects of parameter $\boldsymbol{\lambda}$ on the final ranking order. Kahneman and Tversky [15] suggested that the value of $\lambda$ is between 2.0 and 2.5. The practice example with basic data presented in Table 1 is used to conduct the experiment. This test varies parameter $\boldsymbol{\lambda}$ from 2.0 to 2.5. During the experiment, parameter $\alpha$ is set to be 0.88 . The results shown in Table 8 reveal that ERVD is a robust methodology. The relative coefficient increases as $\boldsymbol{\lambda}$ increases. However, $\boldsymbol{\lambda}$ in the suggested range, 2.0 to 2.5 , does not affect the final ranking order at all.

Table 8 . Results obtained by ERVD with parameter $\lambda$ varied

\begin{tabular}{|c|c|c|c|c|c|c|c|c|c|c|c|c|}
\hline & \multicolumn{2}{|c|}{$\lambda=2.0$} & \multicolumn{2}{|c|}{$\lambda=2.1$} & \multicolumn{2}{|c|}{$\lambda=2.25$} & \multicolumn{2}{|c|}{$\lambda=2.3$} & \multicolumn{2}{|c|}{$\lambda=2.4$} & \multicolumn{2}{|c|}{$\lambda=2.5$} \\
\hline & $\phi_{\bar{i}}$ & Rank & $\phi_{\bar{i}}$ & Rank & $\phi_{\bar{i}}$ & Rank & $\phi_{i}$ & Rank & $\phi_{\bar{i}}$ & Rank & $\phi_{i}$ & Rank \\
\hline$A_{1}$ & 0.646 & 7 & 0.652 & 7 & 0.660 & 7 & 0.663 & 7 & 0.668 & 7 & 0.672 & 7 \\
\hline $\mathrm{A}_{2}$ & 0.492 & 13 & 0.496 & 13 & 0.503 & 13 & 0.505 & 13 & 0.508 & 13 & 0.512 & 13 \\
\hline$A_{3}$ & 0.877 & 3 & 0.880 & 3 & 0.885 & 3 & 0.886 & 3 & 0.889 & 3 & 0.891 & 3 \\
\hline $\mathrm{A}_{4}$ & 0.512 & 12 & 0.516 & 12 & 0.521 & 12 & 0.523 & 12 & 0.526 & 12 & 0.529 & 12 \\
\hline$A_{5}$ & 0.598 & 9 & 0.603 & 9 & 0.610 & 9 & 0.612 & 9 & 0.616 & 9 & 0.620 & 9 \\
\hline $\mathrm{A}_{6}$ & 0.779 & 4 & 0.786 & 4 & 0.796 & 4 & 0.799 & 4 & 0.805 & 4 & 0.810 & 4 \\
\hline$A_{7}$ & 0.488 & 14 & 0.492 & 14 & 0.498 & 14 & 0.500 & 14 & 0.503 & 14 & 0.506 & 14 \\
\hline $\mathrm{A}_{8}$ & 0.537 & 11 & 0.542 & 11 & 0.549 & 11 & 0.551 & 11 & 0.555 & 11 & 0.559 & 11 \\
\hline $\mathrm{A}_{9}$ & 0.899 & 2 & 0.903 & 2 & 0.908 & 2 & 0.910 & 2 & 0.913 & 2 & 0.916 & 2 \\
\hline$A_{10}$ & 0.553 & 10 & 0.558 & 10 & 0.565 & 10 & 0.567 & 10 & 0.571 & 10 & 0.575 & 10 \\
\hline$A_{11}$ & 0.068 & 17 & 0.069 & 17 & 0.070 & 17 & 0.070 & 17 & 0.071 & 17 & 0.071 & 17 \\
\hline$A_{12}$ & 0.194 & 16 & 0.196 & 16 & 0.199 & 16 & 0.200 & 16 & 0.201 & 16 & 0.203 & 16 \\
\hline $\mathrm{A}_{13}$ & 0.619 & 8 & 0.624 & 8 & 0.632 & 8 & 0.634 & 8 & 0.638 & 8 & 0.642 & 8 \\
\hline $\mathrm{A}_{14}$ & 0.701 & 6 & 0.707 & 6 & 0.716 & 6 & 0.719 & 6 & 0.724 & 6 & 0.729 & 6 \\
\hline $\mathrm{A}_{15}$ & 0.429 & 15 & 0.433 & 15 & 0.438 & 15 & 0.440 & 15 & 0.443 & 15 & 0.446 & 15 \\
\hline$A_{16}$ & 0.969 & 1 & 0.970 & 1 & 0.972 & 1 & 0.972 & 1 & 0.973 & 1 & 0.974 & 1 \\
\hline $\mathrm{A}_{17}$ & 0.755 & 5 & 0.760 & 5 & 0.767 & 5 & 0.769 & 5 & 0.773 & 5 & 0.777 & 5 \\
\hline
\end{tabular}


Experiment 4:

This experiment test hows the reference points affect the final ranking in ERVD. This test is designed using the basic data presented in Table 7. According to prospect theory, decision makers feel stronger about loss than gain. Reference points have direct impact on whether a rating can be taken as "gain" or "loss". Therefore, it is reasonable to assume that a change of reference points may cause a different final ranking order. During this test, $\alpha$ and $\boldsymbol{\lambda}$ are set to be 0.88 and 2.25, respectively. The reference point $\mu_{1}$ is set as 50 . This test varies the reference point $\mu_{2}$ from 20 to 80. Table 9 shows the results. The results show that $\mathrm{A}_{4}$ is ranked first when $\mu_{2}=20$. It also can be observed that the best alternative is changed to $A_{3}$ when $\mu_{2}$ shifts to the right to 40,60, and 80. Figure 2 shows the relative values calculated by value function as we vary the reference point. The decrement in value for $A_{4}$ after a right shift in the reference point $\mu_{2}$ is larger than the decrement in value for $A_{3}$. This is because the original rating for $A_{4}$ with respect to $C_{2}$ is between 20 and 40 . The rating is considered as a "gain" when $\mu_{2}=20$. However, it is considered as a "loss" when $\mu_{2}>30$. According to prospect theory, the value decreasing slope for "loss" is steeper than the value increasing slope for "gain". Therefore, the value of $A_{4}$ decreases more when $\mu_{2}>$ 30. Compared with $A_{4}, A_{3}$ has a less negative effect when $\mu_{2}$ move to 40 since it has a higher rating at 50 .

Table 9. Results obtained by ERVD with reference point of $\mathrm{C}_{2}$ varied

\begin{tabular}{|c|c|c|c|c|c|c|c|c|}
\hline \multirow{2}{*}{} & \multicolumn{2}{|c|}{$\mu_{1}=50, \mu_{2}=20$} & \multicolumn{2}{c|}{$\mu_{1}=50, \mu_{2}=40$} & \multicolumn{2}{c|}{$\mu_{1}=50, \mu_{2}=60$} & \multicolumn{2}{c|}{$\mu_{1}=50, \mu_{2}=80$} \\
\cline { 2 - 9 } & $\boldsymbol{\phi}_{\boldsymbol{i}}$ & Rank & $\boldsymbol{\phi}_{\boldsymbol{i}}$ & Rank & $\boldsymbol{\phi}_{\boldsymbol{i}}$ & Rank & $\boldsymbol{\phi}_{\boldsymbol{i}}$ & Rank \\
\hline $\mathrm{A}_{1}$ & 0.436 & 5 & 0.482 & 5 & 0.516 & 4 & 0.542 & 3 \\
\hline $\mathrm{A}_{2}$ & 0.564 & 3 & 0.595 & 3 & 0.615 & 2 & 0.578 & 2 \\
\hline $\mathrm{A}_{3}$ & 0.675 & 2 & 0.692 & 1 & 0.647 & 1 & 0.594 & 1 \\
\hline $\mathrm{A}_{4}$ & 0.684 & 1 & 0.638 & 2 & 0.581 & 3 & 0.542 & 3 \\
\hline $\mathrm{A}_{5}$ & 0.564 & 3 & 0.518 & 4 & 0.484 & 5 & 0.458 & 5 \\
\hline
\end{tabular}

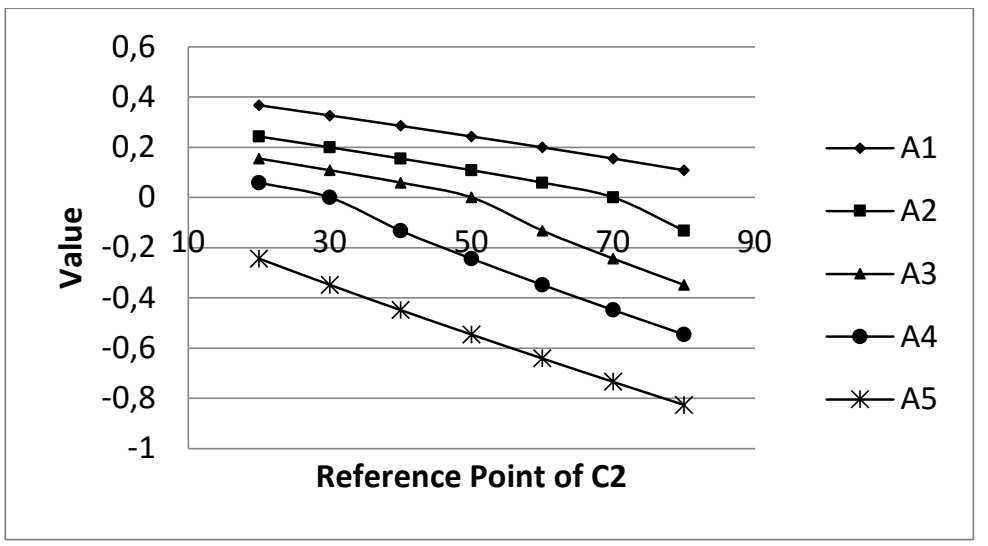

Figure 2. The values according to various reference points. 
According to the above experiments, ERVD provides better performance than does TOPSIS. The proposed method prevents the problem of rank reversals and provides more effective analysis when all the alternatives have the same total utility. ERVD is also a very robust method. The parameter $\lambda$ does not affect the final ranking order if we set its value in the suggested range. However, it should be mentioned that where a decision maker's reference point is placed can have important impacts on the final ranking.

\section{Conclusions}

The TOPSIS and ERVD methods are both based on the calculation of the closeness of coefficients to evaluate alternatives. The best alternative should have the shortest distance from the ideal solution and the farthest distance from the negative ideal solution. The difference between TOPSIS and ERVD is that ERVD considers reference points for each criterion and uses the value function from the Cumulated Prospect Theory to transform the original rating to a relative value. The weighted value distance is determined to calculate the separation measures. However, it should be notified that ERVD does not deal with risk directly since decision criteria values are assumed deterministic. It deals with the risk attitude of decision maker when he/she evaluates the outcomes of decision criteria.

The experiments have demonstrated that ERVD is a feasible methodology for dealing with MCDM problems. Compared with TOPSIS, ERVD has fewer rank reversal problems. Moreover, it provides more effective analysis when all the alternatives have the same total utility.

The setting of reference points impacts the final ranking. Therefore, determining the location of the reference points is an important issue when applying the proposed methodology. A more detailed discussion of how to decide proper reference points for selected criteria and extend the current ERVD method to a group decision environment will be provided in the future.

\section{References}

[1] Baky, I.A., Abo-Sinna, M.A., TOPSIS for bi-level MODM problems, Applied Mathematical Modelling, 37, 2013, 1004-1015

[2] Bernard, R., Classement et choix en présence de points de vue multiples (la méthode ELECTRE), La Revue d'Informatique et de Recherche Opérationelle (RIRO), 8, 1968, $57-75$.

[3] Chen, S. J., Hwang, C. L., Fuzzy Multiple Attribute Decision Making: Methods and Applications, Berlin: Springer-Verlag, Berlin, 1992.

[4] Cheng, S., Chan, C. W., Huang, G. H., Using multiple criteria decision analysis for supporting decision of solid waste management. J. Environ. Sci. Health, 2002, 975990.

[5] Deng, H., Yehm, C. H., Willis, R. J., Inter-company comparison using modified TOPSIS with objective weights, Computers \& Operations Research, 27, 2000, 963973. 
[6] Edwards, K.D., Prospect theory: a literature review, International Review of Financial Analysis, 5, 1, 1996, 19-38.

[7] Gomes, L. F. A. M., Lima, M., TODIM: basics and application to multicriteria ranking of projects with environmental impacts, Foundations of Computing And Decision Sciences, 16, 4, 1991, 113-127.

[8] Gomes, L. F. A. M., Lima, M., From modeling individual preferences to multicriteria ranking of discrete alternatives: a look at prospect theory and the additive difference model. Foundations of Computing and Decision Sciences, 17, 3, 1992, 171-184.

[9] Gomes, L. F. A. M., Rangel, L., An application of the TODIM method to the multicriteria rental evaluation of residential properties, European Journal of Operational Research, 193, 2009, 204-211.

[10] Gomes L. F. A. M., Machado, M., Rangel, L., Behavioral multi-criteria decision analysis: the TODIM method with criteria interactions, Annals of Operations Research, 211, 2013, 531-548.

[11] Gurevich, G., Kliger, D., Levy, O., Decision-making under uncertainty - a field study of cumulative prospect theory, Journal of Banking \& Finance, 33, 7, 2009, 12211229.

[12] Hu, J., Chen P., Yang, L., Dynamic stochastic multi-criteria decision making method based on prospect theory and conjoint analysis, Management Science and Engineering, 8, 2013, 65-71.

[13] Hwang, C. L., Yoon, K., Multiple attribute decision making. In: Lecture Notes in Economics and Mathematical Systems, Springer-Verlag, Berlin,1981.

[14] Ju, Y., Wang, A., Extension of VIKOR method for multi-criteria group decision making problem with linguistic information, Applied Mathematical Modelling, 37, 2013, 3112-3125.

[15] Kahneman, D., Tversky, A., Prospect theory: an analysis of decision under risk. Econometrica, 47, 1979, 263-292.

[16] Khamseh, A.A., Mahmoodi, M., A new fuzzy TOPSIS-TODIM hybrid method for green supplier selection using fuzzy time function, Advances in Fuzzy Systems, http://dx.doi.org/10.1155/2014/841405.

[17] Kim, K. H., Relkin, N. R., Lee, K.M., Hirsch, J., Distinct cortical areas associated with native and second languages, Nature, 388, 1997, 171-174.

[18] Kruskal J.B., Multidimensional scaling by optimizing goodness of fit to a non metric hypothesis, Psychometrika, 29, 1, 1964, 1-27.

[19] Lai, Y. J., Liu, T.Y., Hwang, C. L., TOPSIS for MODM, European Journal of Operational Research, 76, 1994, 486- 500.

[20] Lourenzutti, R., Krohling, R.A., The Hellinger distance in multicriteria decision making: an illustration to the TOPSIS and TODIM methods, Expert Systems with Applications, 41, 9, 2014, 4414-4421.

[21] Opricovic, S., Multicriteria Optimization of Civil Engineering Systems, Faculty of Civil Engineering, Belgrade, 1998.

[22] Opricovic S., Tzeng, G. H., Compromise solution by MCDM methods: a comparative analysis of VIKOR and TOPSIS, European Journal of Operational Research, 156, 2, 2004, 445-455.

[23] Saaty, T. L., The Analytic Hierarchy Process, McGraw-Hill, New York, 1980. 
[24] Shih, H. S., Shyur, H. J., Lee, E. S., An extension of TOPSIS for group decision making, Mathematical and Computer Modelling, 45, 2007, 801-813.

[25] Tversky, A., Kahneman, D., Advances in prospect theory: cumulative representation of uncertainty, Journal of Risk and Uncertainty, 5, 4, 1992, 297-323.

[26] Wang, J.Q., Wu,J.T., Wang, J., Zhang, H.U., Chen, X.H., Multi-criteria decisionmaking methods based on the Hausdorff distance of hesitant fuzzy linguistic numbers, Soft Computing, Feb. 2015, in press.

[27] Wang, Y. M., Luo, Y., On rank reversal in decision analysis, Mathematical and Computer Modelling, 49, 5-6, 2009, 1221-1229.

[28] Yoon, K., A reconciliation among discrete compromise solutions, Journal of perational Research Society, 38, 3, 1987, 272-286.

[29] Yoon, K., Hwang, C. L., Manufacturing plant location analysis by multiple attribute decision making: part I - single-plant strategy, International Journal of Production Research, 23, 1985, 345-359.

[30] Yue, Z., An extended TOPSIS for determining weights of decision makers with interval numbers, Knowledge-Based Systems, 24, 2011, 146-153.

[31] Zanakis, S. H., Solomon, A., Wishart, N., Dublish, S., Multi-attribute decision making: a simulation comparison of select methods, European Journal of Operational Research, 107, 1998, 507-529.

Received 28.11.2014, accepted 28.05.2015 